\title{
Case of Legionnaires' disease in a neonate following a home birth in a heated birthing pool, England, June 2014
}

N Phin ${ }^{1}$, T Cresswell ${ }^{1}$, F Parry-Ford (frances.parryford@phe.gov.uk) ${ }^{1}$, on behalf of the Incident Control Team ${ }^{2}$

1. Public Health England, London, United Kingdom

2. The members of the team are listed at the end of the articl

Public Health England was notified of Legionnaires' disease in a neonate following a home birth in a heated birthing pool filled from the domestic hot water supply two weeks earlier. We describe the incident, sampling results, and public health actions. It is recommended that heated birthing pools should not be used for home births. Neonates developing pneumonia within 14 days of labour or birth in any birthing pool should be tested for Legionnaires' disease.

In early June 2014, Public Health England (PHE) were notified that Legionella pneumophila was identified in bronchoalveolar lavage specimens from a neonate requiring extracorporeal membrane oxygenation (ECMO). The neonate was born at home in a heated birthing pool which had been filled approximately two weeks before birth. The baby became unwell on Day 3 and was admitted to hospital on Day 5 , requiring immediate respiratory support followed by ECMO on Day 6, at which time the bronchoalveolar lavage sample was taken. The result was later confirmed as L. pneumophila serogroup1 ST 48.

\section{Background}

Legionnaires' disease is a severe pneumonia usually caused by inhaling water droplets containing Legionella bacteria. It is very rare in children. During 2012, only $0.5 \%$ of all reported European cases of Legionnaires' disease were in persons under the age 19 years [1]. However, several instances of infection among neonates are documented, usually in association with hospital water systems or respiratory equipment [2-4]. We are aware of three published instances of neonatal Legionnaires' disease associated with birthing pools [5-7]. Two cases were related to birthing pools in hospitals in 1999 and 2002 [5,6]. The third case occurred following a home birth in a domestic spa pool in 1999 , and was fatal [7].

In the United Kingdom (UK), there are companies who hire birthing pools for domestic use. The majority of these are filled at the time of onset of labour and then emptied. However, some products incorporate a heating and recirculation system, and may be filled and operated for up to two weeks before to birth.

\section{Public health actions}

Initial public health response

A multi-agency incident control team was convened to investigate the incident and institute control measures. The supplier who had hired out the pool was contacted and voluntarily recalled all heated pools that were currently out for hire. A national alert was sent out to National Health Service (NHS) staff by NHS England, advising that this type of pool should not be used in the home setting and raising awareness with neonatologists and microbiologists. PHE issued an internal briefing and initially identified 10 other suppliers in England. The local regulating authorities in which these suppliers were based were contacted and advised that local suppliers should recall heated pools that were in use.

\section{Environmental investigations}

The birthing pool used by the case had been drained but not returned to the supplier and so it was possible to obtain swabs and some water samples. Samples were also taken from the domestic water system in the house where the neonate was born and from other birthing pools which had been returned to the supplier and cleaned ready for hiring out.

Using polymerase chain reaction (PCR), three swabs from the birthing pool used by the case were found to be positive for Legionella spp and L. pneumophila. Further analysis was undertaken at the Respiratory and Vaccine Preventable Bacteria Reference Unit at PHE Colindale, and L. pneumophila serogroup 1 ST48 was confirmed.

Samples from the domestic hot water system and from other birthing pools held by the supplier were negative for L. pneumophila in both PCR and culture. The results 
of the environmental and clinical samples support the hypothesis that the baby acquired the infection from the water in the heated birthing pool.

\section{Further public health response}

Six companies were finally identified in England that together hired out around 60 birthing pools incorporating a heater and recirculation pump. Three other companies acted as agents or intermediaries, and two had ceased trading. The heated birthing pools were either adapted spa pools or custom-made from spa pool components. The recommended disinfection and maintenance routines differed between the suppliers and there was no specific advice in relation to Legionella control provided to customers by suppliers.

A risk assessment was undertaken by national experts in Legionnaires' disease and the control of Legionella in water systems as follows:

- Neonates can be at particular risk of very severe illness if they develop lung infections.

- Due to the potential for microbial growth it is not considered good practice to recirculate heated water for prolonged periods of time, i.e. more than a week [8], even with filtration and chemical disinfection.

- The temperature at which the water in the birthing pool is maintained is within the optimal range for the growth of Legionella and other pathogenic organisms.

- Chemical regimes to disinfect water that require manual biocide dosing are dependent on good user compliance, making this approach at risk control unsuitable for use in the domestic setting.

- The skin and mucous membranes of neonates can be particularly sensitive to chemical exposure. It is not clear whether the recommended dosing levels would achieve effective control of Legionella while at the same time avoiding exposure risks to the neonate.

- The information available to those hiring the pools recommends use of the filled pools by family members before use at the time of labour. This will increase the overall organic and bacterial load and reduce effectiveness of the chemical regime.

- The birthing pools from the suppliers which have been reviewed to date contain pipework and consequently may harbour biofilm. This could be difficult to remove during cleaning and could be the source of Legionella during any subsequent use.

- Legionella may be present in up to $10-20 \%$ of household water supplies, which constitutes a potential contamination source when the birthing pools are filled from a domestic source.

- Although aspiration of fluid by babies at birth is an uncommon event, the likelihood of acquiring Legionnaires' disease, should this happen, is increased.

\section{Discussion and conclusions}

It is likely that a combination of recirculation of heated water and a disinfection regime that was inadequate resulted in growth of Legionella in the birthing pool over the two week period. During birth, the baby was probably exposed to Legionella, possibly via aspiration of water. Although there is previous evidence of transmission of Legionella to neonates via birthing pools at home [7], this is the first reported case within Europe and the first for 10 years. No national or international standard or guidance for the safe use of heated birthing pools in the home appears to have been developed, and birthing pools are not specifically covered in wider guidance on the safe operation of spa pools [8].

Until the manufacturers and suppliers are able to provide evidence of a system that is safe to use, PHE recommends that heated birthing pools (incorporating a recirculation pump and heater), filled in advance of labour, should not be used for labour or birth in the home setting. This recommendation does not apply to hospital birthing pools or to pools in the home that are filled immediately prior to birth.

As with adults, prompt identification and treatment with antibiotics effective against Legionella reduces morbidity and mortality [9]. However, the relative rarity of Legionnaires' disease among children and neonates may result in reduced suspicion amongst clinicians, and a delay in recognition and treatment. We recommend that all neonates who develop a severe respiratory infection in the 14 days following labour or birth in any birthing pool are screened for Legionella.

\section{Note added in proof:}

On 17 July 2014, results were obtained from samples from another five heated birthing pools, taken by local authorities following the PHE advice. Three pools tested positive by PCR for Legionella species. In two of them (and in the index pool), other organisms including Stenotrophomonas maltophilia, Pseudomonas aeruginosa, Elizabethkingia meningoseptica, Enterobacter sp. and Cupriavidus sp. were cultured and identified by MALDI-TOF mass spectrometry.

This reinforces serious concerns about the safety of heated birthing pools (incorporating a recirculation pump and heater), filled in advance of labour and used in the home setting.

Members of the incident management team

PHE - Tricia Cresswell (Chair), Nick Phin, Jimmy Walker, Heather Aird, Karen Lloyd, Georgina Fletcher, Anne Halewood, Kelly Stoker, Alison Mason, Lisa Harvey-Vince, Tim Harrison, Vicki Chalker, Baharak Afshar, Samuel Collins. Local Authority (a)- Carol Wood, Stewart Sorrell, Lorna Elliott; Local Authority (b) - Colin Giddings, Laura Annetts; NHS England- Michele Upton, Kate Morrow; Hospital (c) NHS FT -Julie Samuel; Hospital (d) NHS FT- Joanne Crawford; Health and Safety Executive - Paul McDermott; Royal College of Midwives - Louise Silverton. Acknowledgements

The authors would like to acknowledge the contribution of all members of the incident control team in the response to the incident. 
None declared.

\section{Authors' contributions}

$\mathrm{N}$ Phin, $\mathrm{T}$ Cresswell and F Parry-Ford drafted and revised the manuscript. All members of the incident control team contributed to the gathering of information and analysis.

\section{References}

1. European Centre for Disease Prevention and Control (ECDC) Legionnaires' disease in Europe, 2012. Stockholm: ECDC; 2014. Available from: http://ecdc.europa.eu/en/publications/ Publications/legionnaires-disease-surveillance-2012.pdf

2. Yiallouros PK, Papadouri T, Karaoli C, Papamichael E, Zeniou $M$, Pieridou-Bagatzouni D, et al. First outbreak of nosocomial Legionella infection in term neonates caused by a cold mist ultrasonic humidifier. Clin Infect Dis. 2013;57(1):48-56. http://dx.doi.org/10.1093/cid/cit176

3. Shachor-Meyouhas Y, Kassis I, Bamberger E, Nativ T, Sprecher $\mathrm{H}$, Levy $\mathrm{I}$, et al. Fatal hospital-acquired Legionella pneumonia in a neonate. Pediatr Infect Dis J. 2010;29(3):280-1. http://dx.doi.org/10.1097/INF.ob013e3181c176c9

4. Aubert G, Bornstein N, Rayet I, Pozzetto B, Lenormand PH. Nosocomial infection with Legionella pneumophila serogroup 1 and 8 in a neonate. Scand J Infect Dis. 1990;22(3):367-70. http://dx.doi.org/10.3109/00365549009027062

5. Franzin L, Scolfaro C, Cabodi D, Valera M, Tovo PA. Legionella pneumophila pneumonia in a newborn after water birth: a new mode of transmission. Clin Infect Dis. 2001;33(9):e103-4. http://dx.doi.org/10.1086/323023

6. Schrijver DK. Legionairsziekte bij een pasgeborene na een onderwaterbevalling [Legionnaires' disease in a newborn after an underwater birth]. Vlaams infectieziektebulletin. 2002(1):p8-9. Dutch. Available from: http://www.

infectieziektebulletin.be/defaultSubsite.aspx?id=10078\#. U8PoN7EghnU

7. Nagai T, Sobajima H, Iwasa M, Tsuzuki T, Kura F, AmemuraMaekawa J, et al. Neonatal sudden death due to Legionella pneumonia associated with water birth in a domestic spa bath. J Clin Microbiol. 2003;41(5):2227-9. http://dx.doi.org/10.1128/JCM.41.5.2227-2229.2003

8. Health Protection Agency (HPA). HSE document. Management of spa pools. Controlling the risks of infection. London: HPA; 2006. ISBN: 090114480 o. Available from: http://www.hpa. org.uk/webc/hpawebfile/hpaweb_c/1200471667418

9. Greenberg D, Chiou CC, Famigilleti R, Lee TC, Yu VL. Problem pathogens: paediatric legionellosis--implications for improved diagnosis. Lancet Infect Dis. 2006;6(8):529-35. http://dx.doi.org/10.1016/S1473-3099(06)70553-9 